\title{
Low Potential and Non-Enzymatic Hydrogen Peroxide Sensor Based on Copper Oxide Nanoparticle on Activated Pencil Graphite Electrode
}

\author{
Mohammad Ali Kamyabi* and Nasim Hajari \\ Department of Chemistry, Colleges of Science, University of Zanjan, 4537138791 Zanjan, Iran
}

\begin{abstract}
An electrochemical sensor for $\mathrm{H}_{2} \mathrm{O}_{2}$ determination was prepared by electrodepositing copper oxide nanoparticles on the activated pencil graphite electrodes. At first, a study has been made of the optimum conditions for chemical activation of the pencil graphite electrodes (APGE) and then the activated pencil graphite electrode was modified with copper oxide nanoparticles (CuO/APGE) and used as a non-enzymatic hydrogen peroxide sensor. The morphology of the modified electrode surface was investigated by scanning electron microscopy (SEM). Upon the addition of $\mathrm{H}_{2} \mathrm{O}_{2}$, the modified electrode (CuO/APGE) exhibits significant oxidation of $\mathrm{H}_{2} \mathrm{O}_{2}$ with starting potential around $+0.05 \mathrm{~V}$ (vs. $\mathrm{Ag} / \mathrm{AgCl}$ ) which dramatically decreases the overpotential of $\mathrm{H}_{2} \mathrm{O}_{2}$ oxidation. Under the optimal experiment conditions, the electrocatalytic response current of this sensor was proportional to the $\mathrm{H}_{2} \mathrm{O}_{2}$ concentration in the range of $5.0 \times 10^{-6}$ to $1.6 \times 10^{-3} \mathrm{~mol} \mathrm{~L}^{-1}$ with a detection limit down to $0.21 \mu \mathrm{mol} \mathrm{L} \mathrm{L}^{-1}$ (signal/noise $=3$ ). The sensitivity was calculated to be $4.75 \mu \mathrm{AL} \mathrm{mmol}{ }^{-1}$. The electrochemical active surface area and the catalytic rate constant of hydrogen peroxide electro-oxidation were calculated. The $\mathrm{H}_{2} \mathrm{O}_{2}$ sensor exhibited a low detection limit, a good signal reproducibility (relative standard deviation $(\mathrm{RSD}), \mathrm{n}=4) 2.36 \%$ and the accurate measurements in milk as the real sample.
\end{abstract}

Keywords: pencil graphite electrode, non-enzymatic hydrogen peroxide sensor, electocatalysis, $\mathrm{CuO}$ nanoparticle

\section{Introduction}

Hydrogen peroxide is an important chemical because it has attractive features like anti-bacterial property, decolorizing and oxidizing agent. ${ }^{1}$ Widespread application in biology, as a product of oxidase-catalyzed reactions, industry and food make $\mathrm{H}_{2} \mathrm{O}_{2}$ as an attractive chemical to develop reliable and rapid detection methods for accurately monitoring of its concentration. Moreover, outstanding application in fuel cells as a carbon-free energy carrier and a strong oxidant in direct peroxide-peroxide fuel cell was recently developed. ${ }^{2}$

Various detection methods for hydrogen peroxide determination have been developed. ${ }^{3-5}$ Among them, the electrochemical method is preferable for its simplicity, high sensitivity and low detection limit. Considering the high catalytic activity and selectivity of enzymes for certain reactions, various enzymatic electrochemical biosensors have been constructed for the detection of hydrogen peroxide with excellent sensitivity, high selectivity and

*e-mail: makamyabi@gmail.com rapid response, ${ }^{6}$ but the sensitivity of these sensors can be easily affected by temperature, $\mathrm{pH}$ value, humidity and toxic chemicals. Fabricated enzymatic sensors suffered greatly from the chief drawback of poor instability due to the intrinsic nature of enzymes. To solve this problem, the non-enzymatic sensors based on the direct oxidation of hydrogen peroxide have been explored for practical applications. ${ }^{7}$ Due to good reproducibility, low cost, fast response, high sensitivity, low detection limit, and high stability in aggressive environment, non-enzymatic amperometric sensors for direct determination of hydrogen peroxide have attracted considerable attention. ${ }^{8}$ At the opposite, one of the key problems in determination of non-enzymatic hydrogen peroxide is its high overpotential on the ordinary electrodes. Thus, the exploitation of new electrocatalyst with low overpotential has been intensively investigated during the past several decades.

Electrochemically active nanomaterials consisting of platinum, ${ }^{9}$ gold $^{10}$ and carbon nanotubes ${ }^{11-13}$ have been extensively studied for the electrochemical sensors, because they have large surface-to-volume ratio and increased catalytic activities. Of these, $\mathrm{CuO}$ nanomaterials are one of 
the promising candidates for the active electrode material due to their distinctive properties such as high stability and good electrical properties. Different synthetic methods have been studied for the preparation of $\mathrm{CuO}$ nanoparticles with various morphologies, including nanowire, nanosheet, nanorod, and nanoflower. ${ }^{14,15}$ Although most of metallic $\mathrm{Cu}^{0}$ nanomaterials are not stable enough to be used for electroanalysis because they are easily oxidized in air or aqueous solution, chemically more stable $\mathrm{CuO}$ nanomaterials have been studied for various applications including electrochemical $\mathrm{H}_{2} \mathrm{O}_{2}$ sensors. ${ }^{11}$ The interesting occurrence of the growth of $\mathrm{CuO}$ nanowires during the in situ oxidation of copper in air has been reported intensively. ${ }^{16}$ Although this method can be categorized as a low cost method, it requires high temperature, high pressure, complex additives and long reaction time. ${ }^{17}$

The development of low-cost and sensitive electrodes for various electroanalytical applications is interested. The pencil graphite is easily accessible and useful material to prepare the modified electrode. The attractive property of a pencil graphite electrode (PGE) is its higher level of porosity compared to the glassy carbon electrode. Indeed, better intrinsic characteristics of the pencil graphite are attributed to its composite, consisting of graphite, polymeric binder and other additives (like clays).$^{18}$ Indeed, the electron transfer properties of carbon electrodes can be improved by some types of pretreatment, which can be called the electrode "activation". The term "activation" has been used frequently to describe procedures for increasing the reactivity of carbon electrodes, often for the purpose of detecting a specific analyte. "Activation" can be involved in more than one mechanism in terms of its effects on the electrode surface. ${ }^{19}$ Many "activation" procedures are in fact cleaning steps and used to remove surface layers resulting from handling or impure materials used for polishing. Frequently, electrochemical oxidation or reduction in various media has long been used to "activate" carbon electrodes. Şentürk and co-authors ${ }^{20}$ applied a potential of $+1.4 \mathrm{~V}$ vs. $\mathrm{Ag} / \mathrm{AgCl}$ for $60 \mathrm{~s}$ on the PGE surface in the selected supporting electrolyte without stirring to obtain a more sensitive and stable analytical signal. In another work, Özcan ${ }^{21}$ used synergic effect of chemical and electrochemical activation to activate the PGE.

Here, a new chemical activation method for the pencil graphite electrode was presented. Indeed, the PGE was chemically activated by stirring in an ethanolic $\mathrm{HCl}$, which has been selected through an optimization method. Then, porous surface of the PGE was decorated with $\mathrm{CuO}$ nanocubes to promote electron transfer rate. This means that at the first step, the surface of the PGE was activated by the soltion of ethanolic $\mathrm{HCl} 0.1 \mathrm{~mol} \mathrm{~L}^{-1}$ to reach the activated PGE (APGE) and then $\mathrm{CuO}$ nanoparticles were electrodeposited on the surface of APGE to fabricate CuO/APGE. The effect of the surface modification on the hydrogen peroxide oxidation was assessed by cyclic voltammetry (CV) and differential pulse voltammetry (DPV). The proposed modified electrode exhibited excellent catalytic activity, dramatic decrease in overpotential and high stability for hydrogen peroxide determination. Indeed, the fast chemical reaction between $\mathrm{H}_{2} \mathrm{O}_{2}$ and $\mathrm{CuO}$ converts $\mathrm{Cu}^{\mathrm{II}}$ to $\mathrm{Cu}^{\mathrm{I}}$ and $\mathrm{H}_{2} \mathrm{O}_{2}$ to $\mathrm{O}_{2}$. As soon as $\mathrm{Cu}^{\mathrm{I}}$ is produced, it is electro-oxidized back to $\mathrm{Cu}^{\mathrm{II}}$ at the electrode surface and $\mathrm{CuO}$ continues the catalytic cycles (Scheme 1). The sensor was successfully used for the determination of hydrogen peroxide in milk samples using differential pulse voltammetric method.

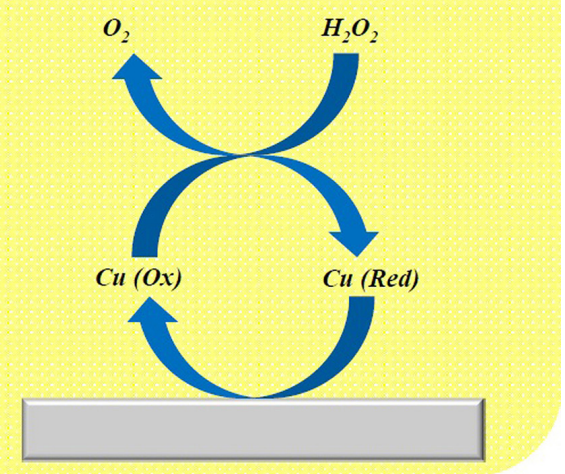

Scheme 1. The schematic of the catalytic mechanism for the $\mathrm{H}_{2} \mathrm{O}_{2}$ oxidation by $\mathrm{CuO}$ nanomaterials.

\section{Experimental}

\section{Reagents and apparatus}

Hydrogen peroxide, ethanol, hydrochloric acid, copper sulfate, sodium sulfate, sodium hydroxide and phosphoric acid were purchased from Merck (Darmstadt, Germany). Double distilled water was used for the preparation of all solutions.

The pencil graphites were purchased as pencil lead from Rotring Co. Ltd. (Germany, R 505210N of type H). The diameter of all the pencil leads were $2.0 \mathrm{~mm}$. All electrochemical experiments were performed using a micro Autolab potentiostat/galvanostat 101. The utilized three-electrode system was composed of modified APGE as the working electrode, $\mathrm{Pt}$ wire as a counter electrode and the potentials were measured versus $\mathrm{Ag} / \mathrm{AgCl}\left(\mathrm{KCl} 3 \mathrm{~mol} \mathrm{~L}^{-1}\right)$ reference electrode. Scanning electron micrograph (SEM) of the PGE, APGE and the modified electrode were performed by using TESCAN/Vega3. Electrochemical impedance spectroscopy (EIS) measurements were 
performed by a Zahner Ennium potentiostat/galvanostat equipped with Thales USB software.

\section{Preparation of the working electrode}

The body of the pencil lead was tightly coated with a teflon band and the surface of the pencil lead was polished on a sandy paper and weighing paper to a smoothed finish before each use then rinsed with distilled water. Electrical contact with the lead was achieved by bonding a metallic contact to the working electrode. The pencil lead was fixed vertically and immersed in the solution in which the contact was only achieved via the cross section of the lead.

\section{Chemical pretreatment of the PGE}

At the first step, the chemical pretreatment of the surface of polished PGEs was carried out by 15 minutes stirring in ethanolic hydrochloric acid $0.1 \mathrm{~mol} \mathrm{~L}^{-1}$ to fabricate APGE. Ethanolic hydrochloric acid was selected as supporting electrolyte for the chemical activation and comparison with other electrolytes or the anodizing method. Then Cu/APGE was achieved by $\mathrm{Cu}$ electrochemical deposition method on the APGE surface by maintaining the potential at $-0.60 \mathrm{~V}$ vs. $\mathrm{Ag} / \mathrm{AgCl}$ for $240 \mathrm{~s}$ in $0.1 \mathrm{~mol} \mathrm{~L} \mathrm{~L}^{-1} \mathrm{Na}_{2} \mathrm{SO}_{4}$ solution containing $0.02 \mathrm{~mol} \mathrm{~L}^{-1} \mathrm{CuSO}_{4}$. After washing with water, the Cu/APGE was immersed in $0.1 \mathrm{~mol} \mathrm{~L}^{-1}$ $\mathrm{NaOH}$ and repeatedly scanned under the potential range from -0.40 to $+0.90 \mathrm{~V}$ at scan rate of $0.1 \mathrm{~V} \mathrm{~s}^{-1}$ for 25 cycles. Deposition potential, deposition time, number of scans in $\mathrm{NaOH}$ were optimized by the final response to hydrogen peroxide in $0.1 \mathrm{~mol} \mathrm{~L}^{-1} \mathrm{NaOH}$ as supporting electrolyte. During repetitive cyclic potential scanning in the alkaline solution of $0.1 \mathrm{~mol} \mathrm{~L}^{-1} \mathrm{NaOH}, \mathrm{CuO}$ nanocubes were formed on the APGE. The repetitive cyclic voltammograms for the electrochemical deposition of $\mathrm{CuO}$ nanocubes on the APGE in $0.1 \mathrm{~mol} \mathrm{~L}^{-1} \mathrm{NaOH}$ are shown in the Supplementary Information (Figure $\mathrm{S} 1$ ). The anodic peak can be attributed to the oxidation of $\mathrm{Cu}_{2} \mathrm{O}$ and $\mathrm{CuOH}$ to $\mathrm{CuO}$, while the cathodic peak can be attributed to the reduction of $\mathrm{CuO}$ into $\mathrm{Cu}_{2} \mathrm{O}$. During the cyclic potential scanning, all redox peak currents decreased, suggesting that $\mathrm{CuO}$ were formed during the CVs. The mechanism of oxidation in $\mathrm{NaOH}$ media is shown below: ${ }^{22,23}$

$$
\begin{aligned}
& \mathrm{Cu}+\mathrm{OH}^{-} \rightarrow \mathrm{CuOH}+\mathrm{e}^{-} \\
& 2 \mathrm{CuOH} \rightarrow \mathrm{Cu}_{2} \mathrm{O}+\mathrm{H}_{2} \mathrm{O} \\
& \mathrm{Cu}_{2} \mathrm{O}+2 \mathrm{OH}^{-} \rightarrow 2 \mathrm{CuO}+\mathrm{H}_{2} \mathrm{O}+2 \mathrm{e}^{-}
\end{aligned}
$$

Finally, the electrode was rinsed with water. The prepared modified electrode was named as $\mathrm{CuO} / \mathrm{APGE}$.

\section{Results and Discussion}

Selection of supporting electrolyte for activation of the PGE

To select the best electrolyte for activation of the PGE, $\mathrm{K}_{3} \mathrm{Fe}(\mathrm{CN})_{6}$ was used as a known electrochemical probe. The peak currents and the separation of reduction and oxidation peaks potential were investigated as a monitoring factor. ${ }^{19,24,25}$ The oxidation peak current of the voltammetric responses of the APGE in different solution divided on the oxidation peak current of the unmodified PGE was given as an enhancement factor (equation 4). Also, the peak to peak separation was studied to investigate the reversibility of the modified electrodes. Figure 1 shows that a binary mixture of ethanol $\mathrm{HCl} 0.1 \mathrm{~mol} \mathrm{~L}^{-1}$ is a genuine nice enhancement factor. In consistence with enhancement factor, peak to peak separation has the least value in a binary mixture of ethanol $\mathrm{HCl} 0.1 \mathrm{~mol} \mathrm{~L}^{-1}$ (Figure 1). Although using an anodizing step can improve the response slightly, this step was ignored because stirring in ethanolic $\mathrm{HCl}$ achieves a higher efficiency. The $\mathrm{HCl}$ concentration in ethanol was also optimized (data not shown). The concentration of $0.1 \mathrm{~mol} \mathrm{~L}^{-1}$ was chosen as the optimum value for $\mathrm{HCl}$ in the subsequent experiments.

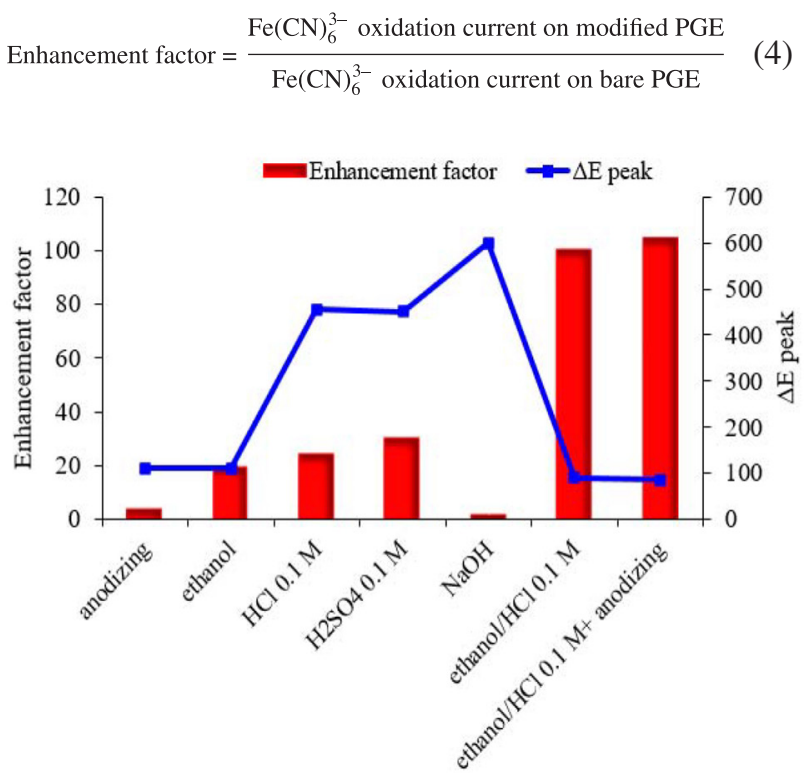

Figure 1. Comparison study of enhancement factor between different methods for activating PGE. The enhancement factor and peak to peak separation of $3.0 \mathrm{mmol} \mathrm{L}^{-1}$ ferocyanide in $\mathrm{KCl} 0.1 \mathrm{~mol} \mathrm{~L}^{-1}$ on the APGE, in the presence of different solutions for $15 \mathrm{~min}$, stirring rate: $250 \mathrm{rpm}$.

The actual mechanism of carbon electrode "activation" is still open to question; obviously, activation of pencil graphite surface is possible but the influence of the inert material, the pasting liquid in carbon paste electrodes, 
for example, must be taken into account. ${ }^{26,27}$ We believe, however, that it is possible to stress the influence of the inert material too much and to de-emphasize the role of the carbon surface when interpreting the observed changes caused by the activation. ${ }^{25}$ In PGE, removal of the pasting liquid probably does make more "active" sites available.

\section{The surface characterization of the CuO/APGE}

The morphology of PGE, APGE and CuO/APGE was studied by scanning electron microscopy characterization. As can be seen, the untreated PGE showed smooth surface morphology (Figures $2 \mathrm{a}$ and $2 \mathrm{~b}$ ), whereas APGE demonstrated the porous structure (Figures $2 \mathrm{c}$ and $2 \mathrm{~d}$ ), indicating that the chemical treatment process increased the surface roughness. This may arise from the breaking of the graphite layers into smaller parts during the chemical treatment process and it can be concluded that the chemical treatment increased the surface roughness. The cubic copper oxide particles are clearly visible on the porous PGE surface (Figures 2e and 2f). The average diameter of the electrodeposited particles was about $100 \mathrm{~nm}$.
Electrochemical impedance spectroscopy was used to investigate the charge transfer property of the $\mathrm{Fe}(\mathrm{CN})_{6}^{3-/ 4-}$ redox couple at the bare and the modified APGE. The Nyquist plot of the EIS includes a semicircular part at high frequencies which refers to the electron-transfer limited process and a linear part at low frequencies which refers to the diffusion limited process. The diameter of semicircular portion is equal to the charge transfer resistance $\left(\mathrm{R}_{\mathrm{ct}}\right)$, which shows the kinetic of electron transfer of the redox probe at the electrode interface. Figure 3 demonstrates that the $\mathrm{R}_{\mathrm{ct}}$ value dramatically decreased after ethanolic $\mathrm{HCl}$ treatment. As expected, carbon electrodes, often for the purpose of detecting a specific analyte, need some types of pretreatments. The $\mathrm{R}_{\mathrm{ct}}$ value was changed significantly by deposition of $\mathrm{CuO}$ nanocubes on the APGE.

In consistence with EIS results, cyclic voltammogram of $\mathrm{Fe}(\mathrm{CN})_{6}{ }^{3-14-}$ before and after deposition of $\mathrm{CuO}$ was illustrated in Supplementary Information (Figure S2). As can be seen in Figure $\mathrm{S} 2, \mathrm{Fe}(\mathrm{CN})_{6}{ }^{3-4-}$ has a reversible behavior with the peak to peak separation of about $70 \mathrm{mV}$ and $\mathrm{i}_{\mathrm{a}} / \mathrm{i}_{\mathrm{c}}$ is equal to 1 , on the surface of the CuO/APGE electrode.
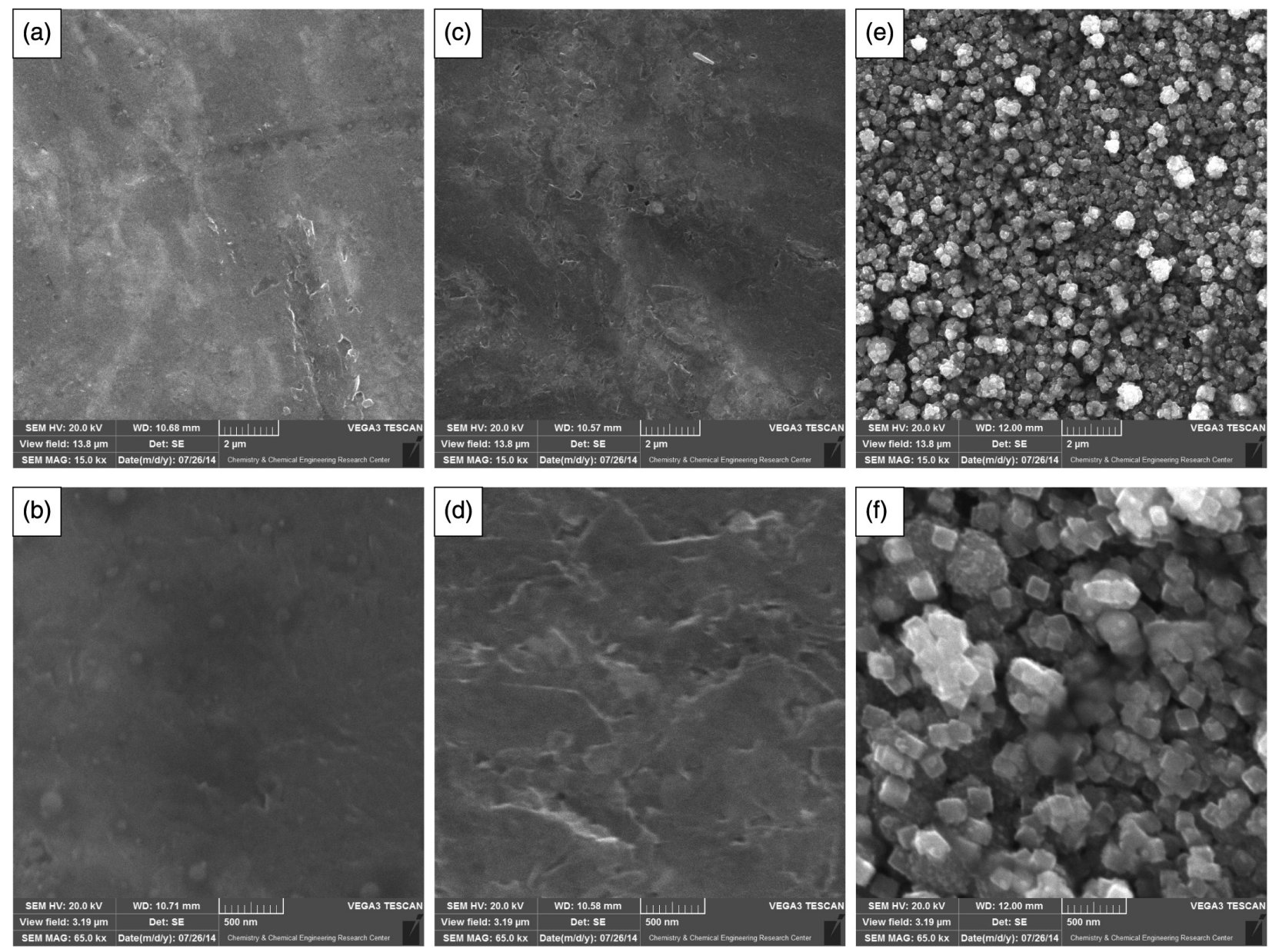

Figure 2. The SEM images of (a, b) PGE; (c, d) APGE and (e, f) CuO/APGE at 15.0 (a, c, e) and 65.0 (b, d, f) magnification. 

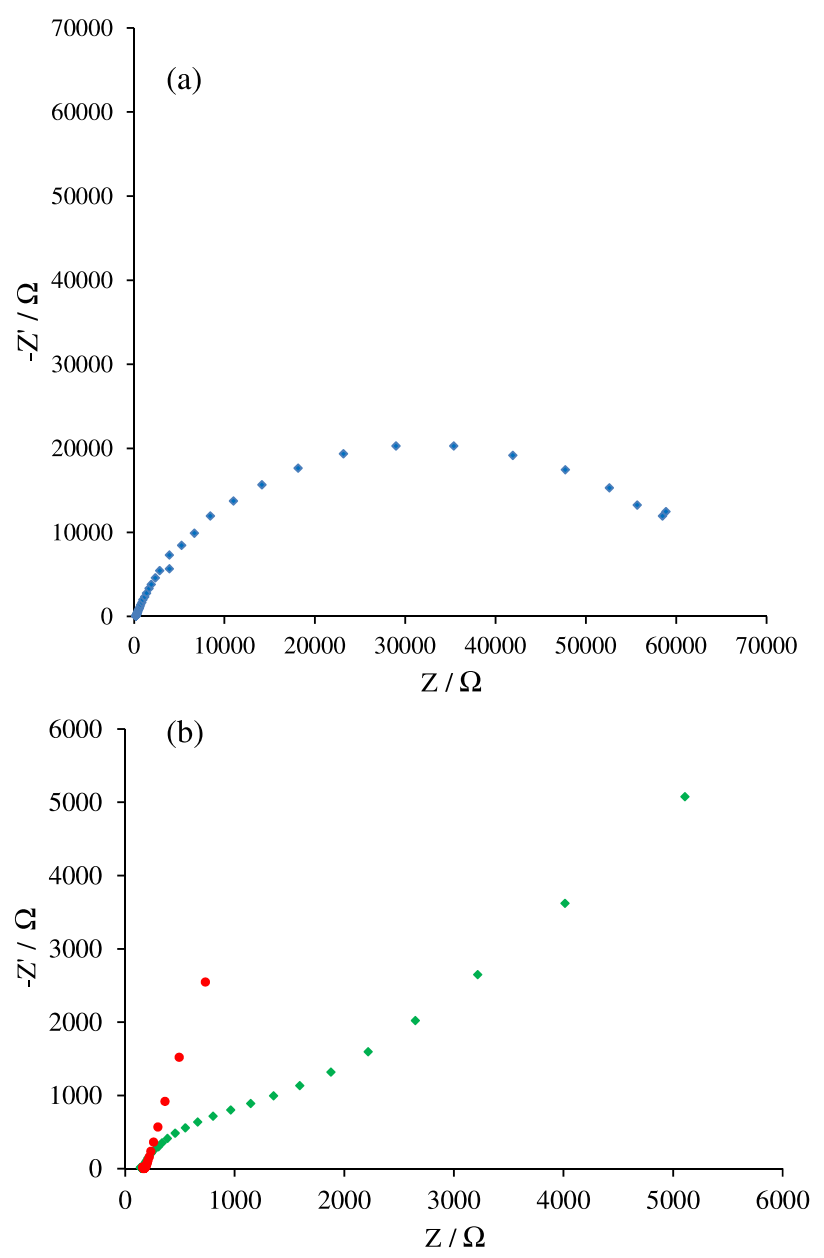

Figure 3. Nyquist plots of (a) PGE; (b) APGE (diamond) and $\mathrm{CuO} / \mathrm{APGE}$ (circle) in a $0.1 \mathrm{~mol} \mathrm{~L}^{-1} \mathrm{KCl}$ containing $5.0 \mathrm{mmol} \mathrm{L}^{-1}$ $\mathrm{Fe}(\mathrm{CN})_{6}^{3-14-}$ at $+0.2 \mathrm{~V} v s . \mathrm{Ag} / \mathrm{AgCl}$, the frequency was scanned from $0.1 \mathrm{~Hz}$ to $100 \mathrm{kHz}$ with the $\mathrm{AC}$ amplitude of $10 \mathrm{mV}$.

Figure 4a shows the cyclic voltammogram of $\mathrm{CuO} / \mathrm{APGE}$ in $0.1 \mathrm{~mol} \mathrm{~L}^{-1} \mathrm{NaOH}$ with scan rate of $0.1 \mathrm{~V} \mathrm{~s}^{-1}$. It includes two peaks during the anodic sweep which can be assigned to $\mathrm{Cu}^{0} / \mathrm{Cu}^{\mathrm{I}}$ and $\mathrm{Cu}^{\mathrm{I}} / \mathrm{Cu}^{\mathrm{II}}$ for the peaks $\mathrm{I}_{\mathrm{a}}$ and $\mathrm{II}_{\mathrm{a}}$, respectively. ${ }^{28,29}$ During the cathodic sweep, two peaks also appeared, which can be assigned to the $\mathrm{Cu}^{\mathrm{II}} / \mathrm{Cu}^{\mathrm{I}}$ and $\mathrm{Cu}^{\mathrm{I}} / \mathrm{Cu}^{0}$, respectively, while the redox peaks of $\mathrm{Cu}^{\mathrm{II}} / \mathrm{Cu}^{\mathrm{III}}$ are not so clear. ${ }^{26}$

To investigate the electrochemical behavior of the modified electrode, cyclic voltammograms of the $\mathrm{CuO} / \mathrm{APGE}$ were recorded in the $\mathrm{pH}$ range of 3.0 to 13.0 (Figure $4 \mathrm{~b}$ ). The results show that increasing the solution $\mathrm{pH}$ the anodic and cathodic peak potentials of the electrode move to more negative potentials. The mean peaks potential $\left(\mathrm{E}^{\circ}\right)$ at various $\mathrm{pHs}$ was calculated as the average value of the anodic and cathodic peaks potential of the voltammograms. As shown in Figure $4 \mathrm{c}$ (inset), increasing the $\mathrm{pH}$ solutions in the $\mathrm{pH}$ range of 3.0-8.0, $\mathrm{E}^{\mathrm{o}}$ of $\mathrm{CuO}$ shift to negative values with the slope of about $29 \mathrm{mV} \mathrm{pH}^{-1}$, which indicates that the redox process is $\mathrm{pH}$ dependent.
Electrocatalytic oxidation of $\mathrm{H}_{2} \mathrm{O}_{2}$

In this work, cyclic voltammetry was used to evaluate the electrocatalytic activity of the $\mathrm{CuO} / \mathrm{APGE}$ towards $\mathrm{H}_{2} \mathrm{O}_{2}$ oxidation. As shown in Figures 5a and 5b, there were no electrochemical response to $\mathrm{H}_{2} \mathrm{O}_{2}$ on the surfaces of the bare PGE and also APGE in the applied potential window, while the CuO/APGE exhibits the oxidation response toward $\mathrm{H}_{2} \mathrm{O}_{2}$ oxidation (Figure $5 \mathrm{c}$ ).

As illustrated in Figure 5d, by increasing the concentration of $\mathrm{H}_{2} \mathrm{O}_{2}$ at the $\mathrm{CuO} / \mathrm{APGE}$, the anodic peak current increased, which indicates good electrocatalytic activity of $\mathrm{CuO} / \mathrm{APGE}$ towards $\mathrm{H}_{2} \mathrm{O}_{2}$ oxidation. Here, in the anodic pathway, $\mathrm{Cu}^{\mathrm{I}}$ is oxidized electrochemically to $\mathrm{Cu}^{\mathrm{II}}$ (i.e., $\mathrm{Cu}_{2} \mathrm{O}+2 \mathrm{OH}^{-} \rightarrow 2 \mathrm{CuO}+\mathrm{H}_{2} \mathrm{O}+2 \mathrm{e}^{-}$). In the presence of $\mathrm{H}_{2} \mathrm{O}_{2}$, according to standard redox potential of $\mathrm{H}_{2} \mathrm{O}_{2}$ to $\mathrm{O}_{2}$ and $\mathrm{CuO}$ to $\mathrm{Cu}_{2} \mathrm{O}$ in the alkaline media (Supplementary Information, Table $\mathrm{S} 1$ ), $\mathrm{Cu}^{\mathrm{II}}$ chemically converts to $\mathrm{Cu}^{\mathrm{I}}$ (i.e., $2 \mathrm{CuO}+\mathrm{H}_{2} \mathrm{O}_{2} \rightarrow \mathrm{Cu}_{2} \mathrm{O}+\mathrm{H}_{2} \mathrm{O}+\mathrm{O}_{2}$ ). As soon as $\mathrm{Cu}^{\text {II }}$ is reduced to $\mathrm{Cu}^{\mathrm{I}}$ by $\mathrm{H}_{2} \mathrm{O}_{2}$, it is electro-oxidized back to $\mathrm{Cu}^{\mathrm{II}}$ at the electrode surface. ${ }^{30}$ Therefore, in the anodic scan, the local concentration of $\mathrm{Cu}^{\mathrm{I}}$ at the electrode surface is increased in the presence of $\mathrm{H}_{2} \mathrm{O}_{2}$, thus the anodic current is increased. Increasing the anodic peak current depends on the $\mathrm{H}_{2} \mathrm{O}_{2}$ concentration. Since the above chemical reaction between $\mathrm{H}_{2} \mathrm{O}_{2}$ and $\mathrm{CuO}$ is fast, nano-copper oxide particles were suitable as mediators to shuttle electrons between $\mathrm{H}_{2} \mathrm{O}_{2}$ and working electrode. ${ }^{23}$

For comparison, $\mathrm{CuO}$ was formed on the bare $\mathrm{PGE}$ and stabilized with cycling in $\mathrm{NaOH}$. The $\mathrm{CuO}$ nanoparticles on the untreated PGE were not stable and a dramatic decrease was observed via cycling in the $\mathrm{NaOH}$ media. This result revealed the basic role of activated treatment on the PGE. This is due to the fact that APGE has a wide surface area and the copper nanoparticles could stand on these sites. $\mathrm{H}_{2} \mathrm{O}_{2}$ electrocatalytic oxidation mechanism at the $\mathrm{CuO} / \mathrm{APGE}$ is indicated in $\mathrm{Scheme} 1$. The $\mathrm{CuO}$ nanoparticles can oxide the $\mathrm{H}_{2} \mathrm{O}_{2}$ to $\mathrm{O}_{2}$ via the generation of $\mathrm{Cu}^{\mathrm{I}}$ by the following reaction: ${ }^{20}$

$2 \mathrm{CuO}+\mathrm{H}_{2} \mathrm{O}_{2} \rightarrow \mathrm{Cu}_{2} \mathrm{O}+\mathrm{H}_{2} \mathrm{O}+\mathrm{O}_{2}$ chemical reaction (5)
$\mathrm{Cu}_{2} \mathrm{O}+2 \mathrm{OH}^{-} \rightarrow 2 \mathrm{CuO}+\mathrm{H}_{2} \mathrm{O}+2 \mathrm{e}^{-}$on the electrode surface

Figure 6a shows the cyclic voltammograms of $1.0 \mathrm{mmol} \mathrm{L}^{-1} \mathrm{H}_{2} \mathrm{O}_{2}$ in $\mathrm{NaOH} 0.1 \mathrm{~mol} \mathrm{~L}^{-1}$ on the CuO/APGE at different scan rates ranging from 10 to $500 \mathrm{mV} \mathrm{s}^{-1}$. The peak currents are linearly proportional to the square root of scan rate in the range of $10-400 \mathrm{mV} \mathrm{s}^{-1}$, indicating a diffusion controlled electron process occurred for $\mathrm{H}_{2} \mathrm{O}_{2}$ 


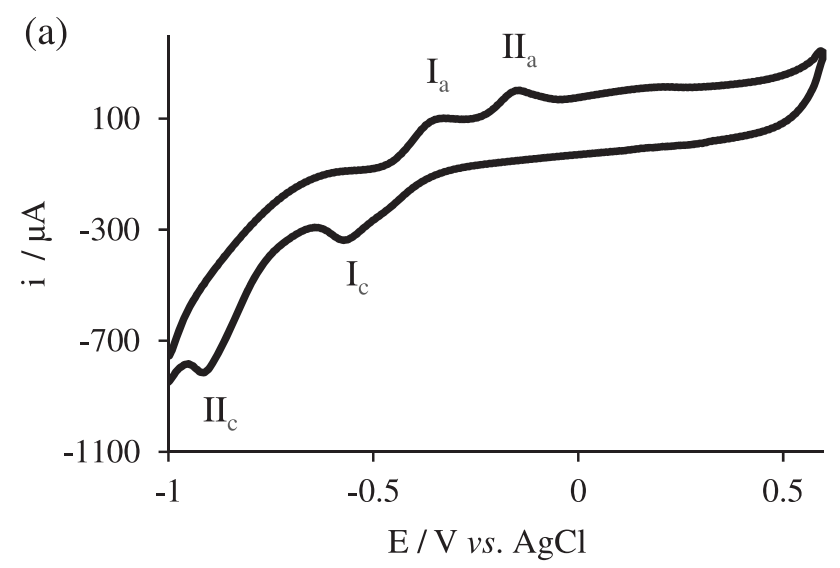

(b)
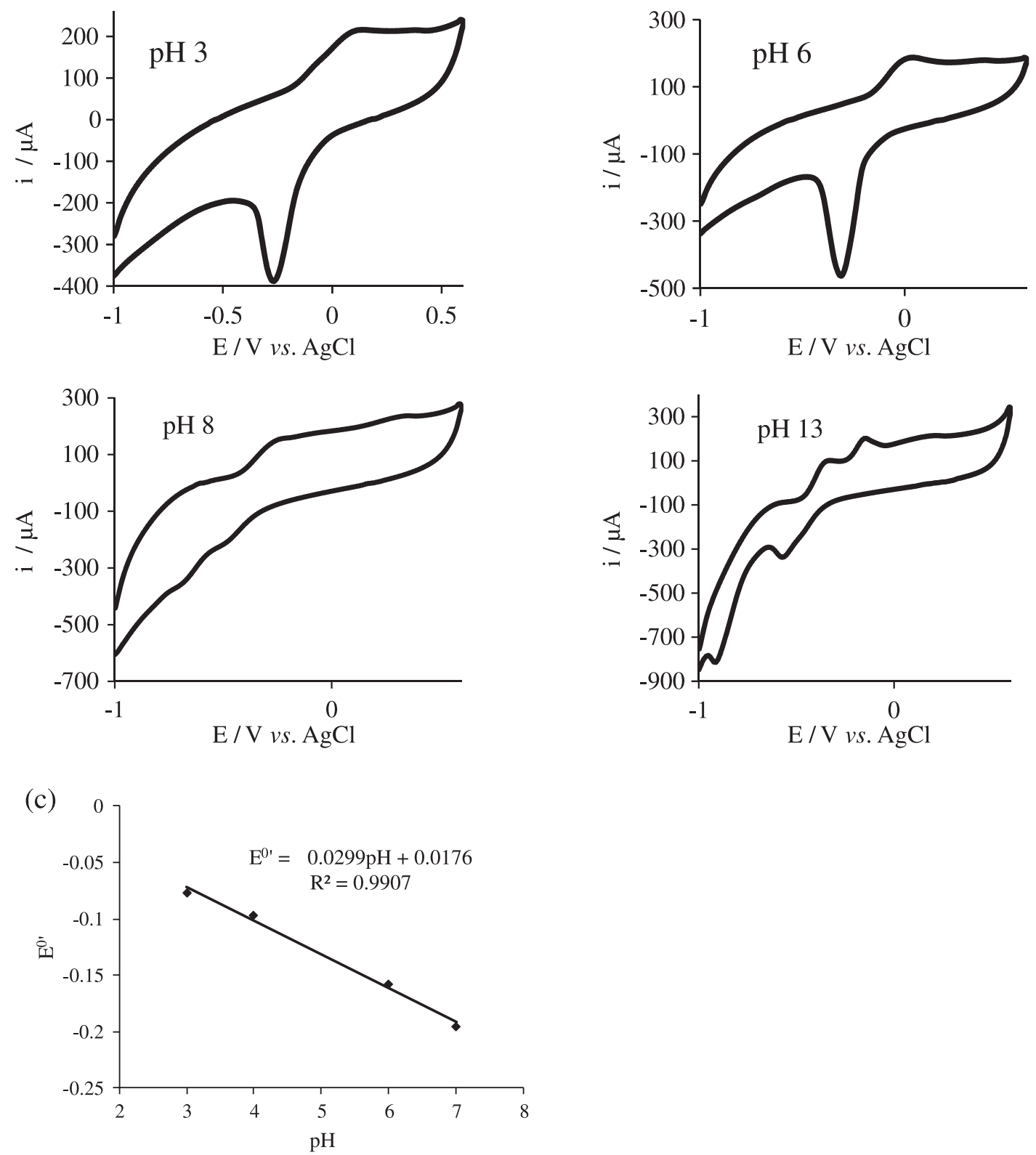

Figure 4. (a) Cyclic voltammogram of CuO/APGE in the $0.1 \mathrm{~mol} \mathrm{~L}^{-1} \mathrm{NaOH}$ with scan rate of $100 \mathrm{mV} \mathrm{s}^{-1}$; (b) effect of pH on the CuO/APGE, scan rate: $100 \mathrm{mV} \mathrm{s}^{-1}$; (c) the inset shows the dependence of $\mathrm{E}^{0}$, vs. $\mathrm{pH}$ in the $\mathrm{pH}$ range of 3.0-8.0. 

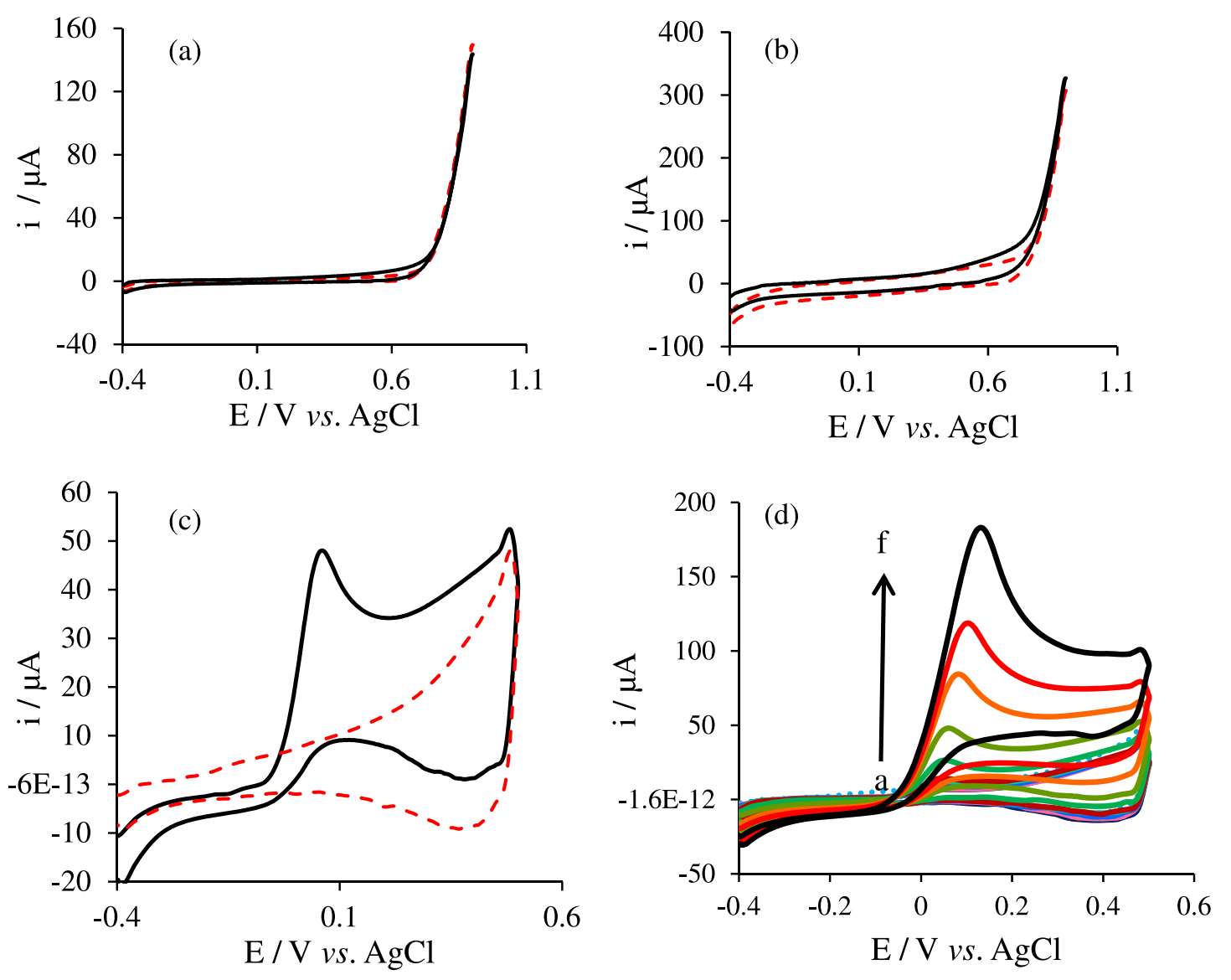

Figure 5. Cyclic voltammogram of (a) PGE; (b) APGE and (c) APGE/CuO in $0.1 \mathrm{~mol} \mathrm{~L}^{-1} \mathrm{NaOH}$, in presence (black solid line) and absence (red dashed line) of $6.0 \mathrm{mmol} \mathrm{L}^{-1} \mathrm{H}_{2} \mathrm{O}_{2}$, scan rate $0.1 \mathrm{~V} \mathrm{~s}^{-1}$; (d) cyclic voltammograms of $\mathrm{CuO} / \mathrm{APGE}$ with addition of $\mathrm{H}_{2} \mathrm{O}_{2}$ from 0.11 to $29.9 \mathrm{mmol} \mathrm{L}^{-1}$ in $0.1 \mathrm{~mol} \mathrm{~L}^{-1}$ $\mathrm{NaOH}$, scan rate $0.1 \mathrm{~V} \mathrm{~s}^{-1}$.

determination, which is the perfect manner for quantitative determinations (Figure 6b). Moreover, the oxidation potential was almost the same at scan rates below $50 \mathrm{mV} \mathrm{s}^{-1}$, suggesting facile charge transfer kinetics over this range of sweep rates. On the other hand, it was found that at scan rates above $50 \mathrm{mV} \mathrm{s}^{-1}$, the oxidation peak potential were increased with scan rate increasing. The values of oxidation potential are proportionate to the logarithm of the current (data not shown). Based on the Tafel theory, the transfer coefficient $(\alpha)$ can be estimated by measuring the variation of peak potential with current. ${ }^{31}$ The transfer coefficient at scan rate $10 \mathrm{mV} \mathrm{s}^{-1}$ in the presence of $1.0 \mathrm{mmol} \mathrm{L}^{-1} \mathrm{H}_{2} \mathrm{O}_{2}$ was obtained as 0.53 .

The chronoamperometry as well as other electrochemical methods was employed for investigation of electrode processes at the modified electrodes. Figure 7 a illustrates the chronoamperometric measurements of the system at the CuO/APGE. This figure represents the current-time curves obtained by setting the working electrode potential at $200 \mathrm{mV} v s . \mathrm{Ag} / \mathrm{AgCl}$ in the absence and presence of hydrogen peroxide. Figure $7 \mathrm{~b}$ shows the experimental plot of $i v s . t^{-1 / 2}$. The slope of the resulting straight line was then plotted against hydrogen peroxide concentration. From the slope and using the Cottrell equation, ${ }^{32}$ the value of diffusion coefficient was found to be $9.55 \times 10^{-6} \mathrm{~cm}^{2} \mathrm{~s}^{-1}$.

$\mathrm{I}=\mathrm{nFAD}^{1 / 2} \mathrm{C} 0 \pi^{-1 / 2} \mathrm{t}^{-1 / 2}$

where I, n, F, A, D, C0, and t refer to the current, number of electrons, Faraday constant, area of the working electrode, diffusion coefficient, initial mole concentration of $\mathrm{Cu}$, and time, respectively.

According to the method described in, chronoamperometric data can also be employed to evaluate the catalytic rate constant of the chemical reaction between the hydrogen peroxide and the active site of the CuO/APGE according to the following equation: ${ }^{33}$

$\mathrm{i}_{\mathrm{c}} / \mathrm{i}_{1}=\gamma^{1 / 2}\left[\pi^{1 / 2} \operatorname{erf}\left(\gamma^{1 / 2}\right)+\exp (-\gamma) / \gamma^{1 / 2}\right]$

where $i_{c}$ is the catalytic current of the CuO/APGE in the presence of hydrogen peroxide, $i_{1}$ is the limiting current in the absence of hydrogen peroxide and $\gamma=\mathrm{kC}_{0} \mathrm{t}$, where $\mathrm{C}_{0}$ is the bulk concentration of hydrogen peroxide $\left(\mathrm{mol} \mathrm{L}^{-1}\right), \mathrm{k}$ is 

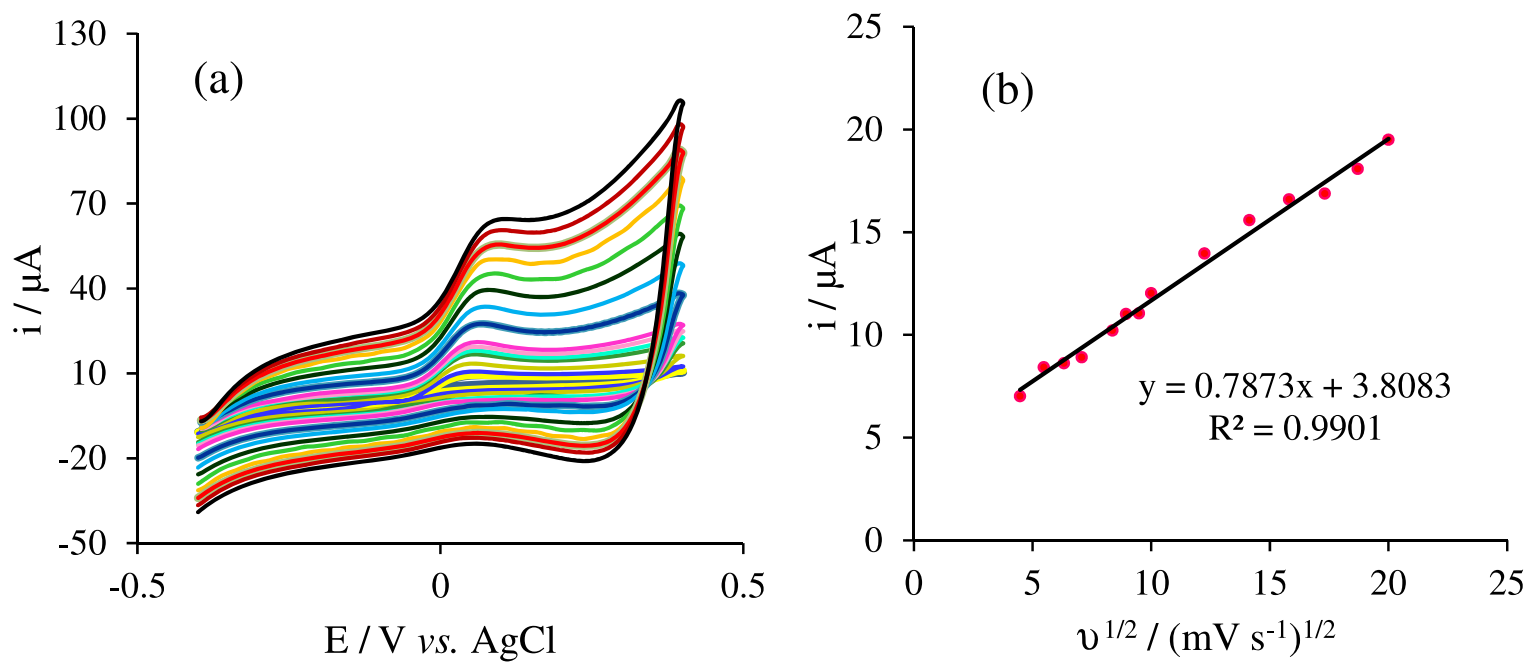

Figure 6. (a) Cyclic voltammograms of $\mathrm{CuO} / \mathrm{APGE} \mathrm{NaOH} 0.1 \mathrm{~mol} \mathrm{~L}^{-1}$ solution containing $1.0 \mathrm{mmol} \mathrm{L}^{-1} \mathrm{H}_{2} \mathrm{O}_{2}$ at the scan rates from 10 to $500 \mathrm{mV} \mathrm{s}^{-1}$; (b) plot of variations of peak currents $\left(\mathrm{i}_{\mathrm{p}}\right)$ versus $v^{1 / 2}$.

the catalytic rate constant $\left(\mathrm{cm}^{3} \mathrm{~mol}^{-1} \mathrm{~s}^{-1}\right)$ and $\mathrm{t}$ is the time elapsed (s), and $\operatorname{erf}\left(\gamma^{1 / 2}\right)$ is the argument of error function. In treatments, it is assumed that hydrogen peroxide is present in large excess rather than $\mathrm{Cu}$ nanocubes, in addition where $\gamma$ exceeds 2 , the error function is almost equal to 1 and the above equation can be considered as follows:

$\mathrm{i}_{\mathrm{c}} / \mathrm{i}_{1}=\gamma^{1 / 2} \pi^{1 / 2}=\pi^{1 / 2}\left(\mathrm{kC}_{0} \mathrm{t}\right)^{1 / 2}$

Based on the slope of the $\mathrm{i}_{\mathrm{c}} / \mathrm{i}_{1} v s . \mathrm{t}^{1 / 2}$ plot (Figure $7 \mathrm{c}$ ), the mean value of $\mathrm{k}$ was found to be $33.47 \mathrm{~cm}^{3} \mathrm{~mol}^{-1} \mathrm{~s}^{-1}$ in the

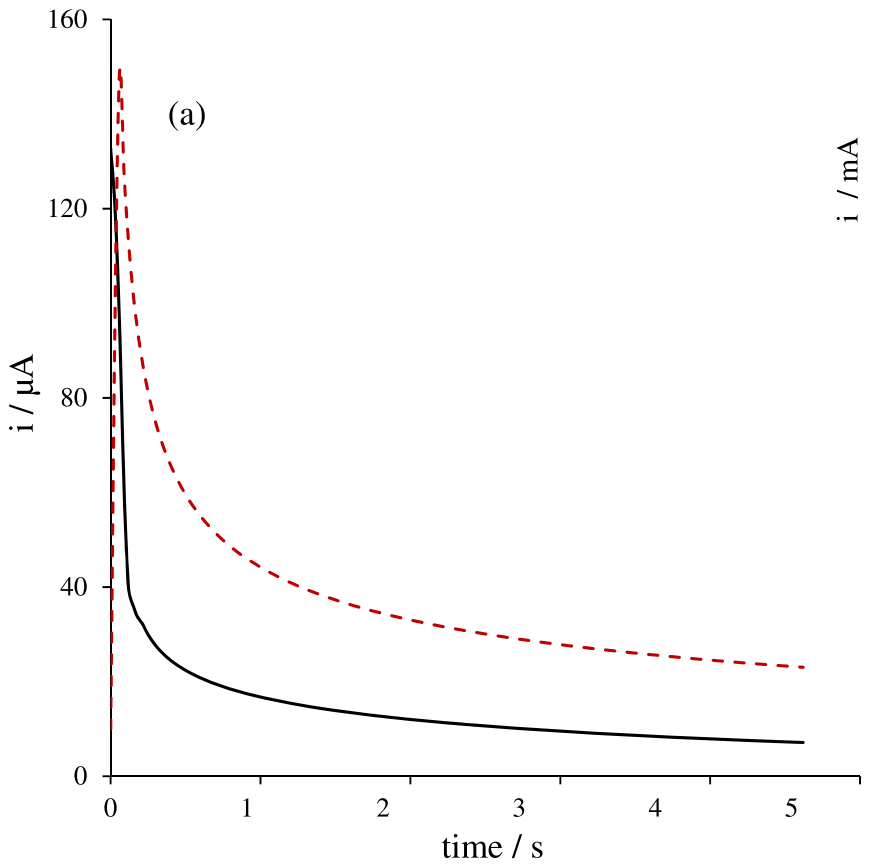

$3.84 \mathrm{mmol} \mathrm{L}^{-1} \mathrm{H}_{2} \mathrm{O}_{2}$ solution. This value for the electron transfer rate constant is comparable with $41.9 \mathrm{~cm}^{3} \mathrm{~mol}^{-1} \mathrm{~s}^{-1}$ for $\mathrm{Hb} / \mathrm{PLE}$, the apparent heterogeneous electron transfer rate constant reported previously. ${ }^{33}$

Differential pulse voltammetric determination of $\mathrm{H}_{2} \mathrm{O}_{2}$ at the CUO/APGE

Due to the more quantitative features of differential pulse voltammetry to cyclic voltammetry method, this eletrochemical technique was employed to obtain the
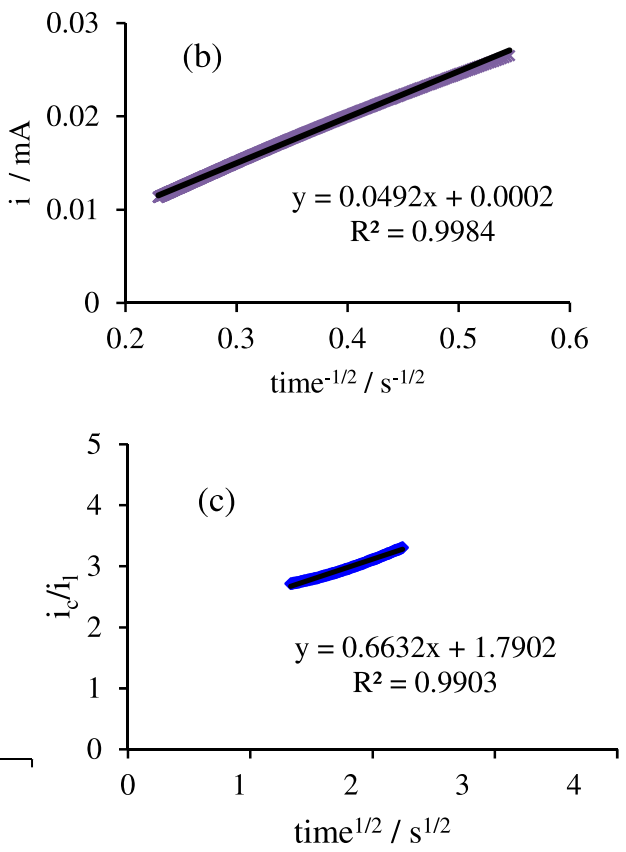

Figure 7. (a) Chronoamperograms of $\mathrm{CuO} / \mathrm{APGE}$ in $0.1 \mathrm{~mol} \mathrm{~L}^{-1} \mathrm{NaOH}$ solution in absence (black solid line) and presence of $3.84 \mathrm{mmol} \mathrm{L}^{-1} \mathrm{H}_{2} \mathrm{O}_{2}(\mathrm{red}$ dashed line), potential step was $0.2 \mathrm{~V}$; (b) dependency of transient current on $\mathrm{t}^{1 / 2}$ for following concentration of hydrogen peroxide; (c) dependence of $\left(\mathrm{i}_{\mathrm{c}} / \mathrm{i}_{1}\right)$ on $\mathrm{t}^{1 / 2}$ derived from the data of chronoamperogram. 

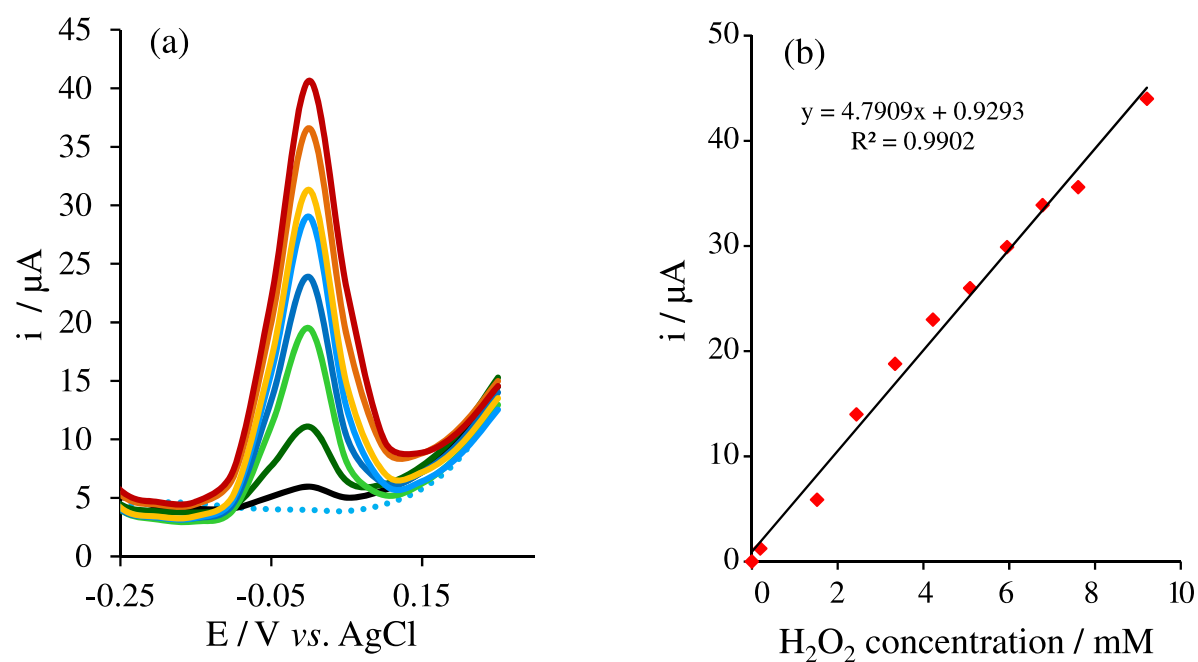

Figure 8. (a) DP voltammograms for hydrogen peroxide determination. The DPV parameters are $\alpha=50 \mathrm{mV}, \tau=50 \mathrm{~ms}, \mathrm{v}=0.1 \mathrm{~V} \mathrm{~s}{ }^{-1}$, and NaOH solution $\left(0.1 \mathrm{~mol} \mathrm{~L}^{-1}\right)$; (b) calibration curve of concentration versus peak current of $\mathrm{H}_{2} \mathrm{O}_{2}$.

analytical figures. In order to obtain the calibration curve, the measurements were performed in $0.1 \mathrm{~mol} \mathrm{~L}^{-1}$ $\mathrm{NaOH}$ solution with the hydrogen peroxide addition in the concentration range of $5.0 \times 10^{-6}$ to $2.6 \times 10^{-3} \mathrm{~mol} \mathrm{~L}^{-1}$ (Figure 8).

The analytical curve is linear in the hydrogen peroxide concentration range from $5.0 \mu \mathrm{mol} \mathrm{L}^{-1}$ to $2.6 \mathrm{mmol} \mathrm{L}^{-1}$ with a limit of detection (LOD) of $0.21 \mu \mathrm{mol} \mathrm{L}^{-1}$. LOD was calculated using the relationship $3 \mathrm{~s} / \mathrm{b}$, where $\mathrm{s}$ is the average of standard deviation of 4 measurements for the blank solution and $\mathrm{b}$ is the sensitivity calculated from the calibration curve slope $\left(4.75 \mu \mathrm{AL} \mathrm{mmol}{ }^{-1}\right)$.

For comparison, the performances of the CuO/APGE and the other hydrogen peroxide sensors reported in literature were listed in Table 1. As can be seen in Table 1, an outstanding feature of the developed sensor is the significant decrease in overpotential for hydrogen peroxide oxidation. Moreover, the presented sensor exhibits comparable analytical figures while it has low cost and easily preparation merits. Although some sensors have a wider linear range, their outstanding low determination potential is an attractive feature in the presented sensor.

Reproducibility and stability of the $\mathrm{H}_{2} \mathrm{O}_{2}$ sensor

Reproducibility and stability are attractive features for sensors. To establish the reproducibility, four modified electrodes were fabricated and their DP voltammetric responses towards $1.0 \mathrm{mmol} \mathrm{L}^{-1} \mathrm{H}_{2} \mathrm{O}_{2}$ were examined. The relative standard deviation ( $\mathrm{RSD}, \mathrm{n}=4$ ) was found to be $2.36 \%$. The storage stability was investigated by recording DP voltammetric response of $1.0 \mathrm{mmol} \mathrm{L}^{-1}$ $\mathrm{H}_{2} \mathrm{O}_{2}$ in $0.1 \mathrm{~mol} \mathrm{~L}^{-1} \mathrm{NaOH}$, during 10 days. CuO/APGE retained $95 \%$ of its initial current response for hydrogen

Table 1. Analytical performances of different modified electrodes for $\mathrm{H}_{2} \mathrm{O}_{2}$ determination

\begin{tabular}{|c|c|c|c|c|c|}
\hline Sensor & $\mathrm{LDR} /\left(\mathrm{mol} \mathrm{L}^{-1}\right)$ & $\begin{array}{c}\mathrm{DL} / \\
\left(\mu \mathrm{mol} \mathrm{L} \mathrm{L}^{-1}\right)\end{array}$ & $\begin{array}{l}\text { Sensitivity / } \\
\left(\mu \mathrm{AL} \mathrm{mmol}{ }^{-1}\right)\end{array}$ & $\begin{array}{l}\text { Oxidation potential / } \\
\qquad \mathrm{v} v \mathrm{Ag} / \mathrm{AgCl}\end{array}$ & Reference \\
\hline Nano- $\mathrm{TiO}_{2}$ and $\mathrm{Pt} / \mathrm{Ti}$ foil & $4 \times 10^{-6}$ to $1.25 \times 10^{-3}$ & 4 & 0.85 & 0.3 & 34 \\
\hline $\begin{array}{l}\text { Pt-implanted/boron-doped diamond } \\
\text { electrode }\end{array}$ & $1.0 \times 10^{-7}$ to $1.0 \times 10^{-5}$ & 0.03 & 21.9 & 0.55 & 35 \\
\hline Copper on porous silicon (Cu/PSi)-CPE & $5.0 \times 10^{-4}$ to $3.78 \times 10^{-3}$ & 0.27 & 13.09 & 0.2 & 23 \\
\hline Carbon nanofiber/GC & $1.80 \times 10^{-4}$ to $2.62 \times 10^{-3}$ & 4 & 3.20 & 0.65 & 36 \\
\hline Carbon nanotube paste electrode & not reported & 20 & 0.8 & 0.95 & 37 \\
\hline AuNPs/MWCNT/PANI & $3.0 \times 10^{-6}$ to $6.0 \times 10^{-4}$ & 0.3 & 3.3 & 0.8 & 38 \\
\hline $\mathrm{Cu} / \mathrm{GC}$ & $2.0 \times 10^{-9}$ to $2.7 \times 10^{-7}$ & 0.0002 & $1.24 \times 10^{-4}$ & 0.2 & 23 \\
\hline $\mathrm{MnO}_{2} / \mathrm{OMC} / \mathrm{GC}$ & $5 \times 10^{-7}$ to $6 \times 10^{-4}$ & 0.07 & $806.8 \mu \mathrm{AL} \mathrm{mmol}{ }^{-1} \mathrm{~cm}^{-2}$ & 0.45 & 39 \\
\hline $\mathrm{CuO} / \mathrm{APGE}$ & $5.0 \times 10^{-6}$ to $1.6 \times 10^{-3}$ & 0.21 & 4.75 & 0.05 & this work \\
\hline
\end{tabular}

PANI: polyaniline; MWCNTs: multiwalled carbon nanotubes; AuNPs: gold nanoparticles; CPE: carbon paste electrode; GC: glassy carbon; OMC: ordered mesoporous carbon; APGE: activated pencil graphite electrode. 
peroxide over a 10 day period. These results indicate that this electrochemical sensor has a good stability and reproducibility, as required for the determination of $\mathrm{H}_{2} \mathrm{O}_{2}$.

Interference study and real sample analysis

The selectivity studies are challenging problems for enzyme-free $\mathrm{H}_{2} \mathrm{O}_{2}$ sensors in the presence of common interfering species, though the naturally coexisting interfering species are highly active at enzyme-free electrode systems. ${ }^{40}$ The DP voltammetric response of the $\mathrm{CuO} / \mathrm{APGE}$ to the consecutive addition of $\mathrm{H}_{2} \mathrm{O}_{2}$ $\left(0.4 \mathrm{mmol} \mathrm{L}^{-1}\right)$ and potentially interfering species such as ascorbic acid, uric acid and glucose $\left(0.4 \mathrm{mmol} \mathrm{L}^{-1}\right)$ in $0.1 \mathrm{~mol} \mathrm{~L}^{-1} \mathrm{NaOH}$, were recorded. In practical conditions, glucose and uric acid did not disturb in the detection of hydrogen peroxide and ascorbic acid interference response is less than $3 \%$. Indeed, the good selectivity can be attributed to dramatic decrease in electrocatalytic oxidation potential of hydrogen peroxide.

To demonstrate electrode suitability and potential application for sample analysis, the $\mathrm{CuO} / \mathrm{APGE}$ was used for the determination of $\mathrm{H}_{2} \mathrm{O}_{2}$ in ultra-high-temperature (UHT) processed milk. Hydrogen peroxide in milk samples presents as a result of enzymatic activity and works as an anti-bacterial agent. ${ }^{41}$ While the amount of hydrogen peroxide in milk is lower than detection limit, the sample was spiked with various amounts of $\mathrm{H}_{2} \mathrm{O}_{2}$ and a recovery test was performed (Table 2). The recovery was about $97.5 \%$ by four replications suggesting that there was no interference from the complex matrix of milk.

Table 2. Results of determination of hydrogen peroxide in the milk samples

\begin{tabular}{lccc}
\hline Detected amount & $\begin{array}{c}\text { Spiked / } \\
\left(\mathrm{mmol} \mathrm{L}^{-1}\right)\end{array}$ & $\begin{array}{c}\text { Found / } \\
\left(\mathrm{mmol} \mathrm{L}^{-1}\right)\end{array}$ & Recovery / \% \\
\hline- & 1.0 & 0.98 & 98 \\
- & 3.0 & 2.91 & 97 \\
\hline
\end{tabular}

\section{Conclusions}

In summary, a low potential electrochemical sensor was presented for hydrogen peroxide determination. A porous electrode with high surface area could be achieved by electrodeposition of $\mathrm{CuO}$ nanocubes on the APGE. The presented sensor is prepared in less than one hour with the lowest cost. The CuO-modified electrode displayed high electrocatalytic activity and fast response to hydrogen peroxide oxidation. This $\mathrm{CuO} / \mathrm{APGE}$ electrochemical sensor has comparable analytical figures with other electrochemical sensors. The relative standard deviation (RSD, $n=4$ ) was $2.36 \%$. These results indicate that this electrochemical sensor has a good reproducibility, as required for the determination of $\mathrm{H}_{2} \mathrm{O}_{2}$.

\section{Supplementary Information}

Supplementary information is available free of charge at http://jbcs.org.br as PDF file.

\section{Acknowledgment}

The authors express their gratitude to the University of Zanjan Research Council for support of this work.

\section{References}

1. Lin, K.-C.; Yin, C.-Y.; Chen, S.-M.; Sens. Actuators, B 2011 , 157, 202.

2. Yang, F.; Cheng, K.; Xue, X.; Yin, J.; Wang, G.; Cao, D.; Electrochim. Acta 2013, 107, 194.

3. Klassen, N. V.; Marchington, D.; McGowan, H. C.; Anal. Chem. 1994, 66, 2921.

4. Sellers, R. M.; Analyst 1980, 105, 950.

5. Paital, B.; BioMed Res. Int. 2014, 2014, ID 342958.

6. Gao, Z.; Liu, J.; Chang, J.; Wu, D.; He, J.; Wang, K.; Xu, F.; Jiang, K.; CrystEngComm 2012, 14, 6639.

7. Wu, H.-X.; Cao, W.-M.; Li, Y.; Liu, G.; Wen, Y.; Yang, H.-F.; Yang, S.-P.; Electrochim. Acta 2010, 55, 3734.

8. Li, K.; Fan, G.; Yang, L.; Li, F.; Sens. Actuators, B 2014, 199 , 175.

9. Guo, S.; Wen, D.; Zhai, Y.; Dong, S.; Wang, E.; ACS Nano 2010, 4, 3959.

10. Maduraiveeran, G.; Ramaraj, R.; J. Electroanal. Chem. 2007, 608, 52.

11. Yang, N.; Chen, X.; Ren, T.; Zhang, P.; Yang, D.; Sens. Actuators, B 2015, 207, 690.

12. Kamyabi, M. A.; Hajari, N.; Turner, A. P.; Tiwari, A.; Talanta 2013, 116, 801.

13. Kamyabi, M. A.; Rahmanian, N.; Anal. Methods 2015, 7, 1339.

14. Song, M.-J.; Hwang, S. W.; Whang, D.; Talanta 2010, 80, 1648.

15. Prathap, M. A.; Kaur, B.; Srivastava, R.; J. Colloid Interface Sci. 2012, 370, 144.

16. Li, A.; Song, H.; Wan, W.; Zhou, J.; Chen, X.; Electrochim. Acta 2014, 132, 42.

17. Lu, L.; Huang, X.; Microchim. Acta 2011, 175, 151.

18. McCreery, R. L.; Advanced Carbon Electrode Materials for Molecular Electrochemistry, vol. 17; Bard, A. J., ed.; Marcel Dekker: New York, 1990, p. 221.

19. McCreery, R. L.; Chem. Rev. 2008, 108, 2646. 
20. Yardım, Y.; Keskin, E.; Levent, A.; Özsöz, M.; Şentürk, Z.; Talanta 2010, 80, 1347.

21. Özcan, A.; Electroanalysis 2014, 26, 1631.

22. Yang, J.; Jiang, L.-C.; Zhang, W.-D.; Gunasekaran, S.; Talanta 2010, 82, 25.

23. Le, W.-Z.; Liu, Y.-Q.; Sens. Actuators, B 2009, 141, 147.

24. Lord Jr., S.; Rogers, L.; Anal. Chem. 1954, 26, 284.

25. Tavares, P. H. C. P.; Barbeira, P. J. S.; J. Appl. Electrochem. 2008, 38, 827.

26. Rice, M. E.; Galus, Z.; Adams, R. N.; J. Electroanal. Chem. Interfacial Electrochem. 1983, 143, 89.

27. Urbaniczky, C.; Lundström, K.; J. Electroanal. Chem. Interfacial Electrochem. 1984, 176, 169.

28. Zhang, Y.; Su, L.; Manuzzi, D.; de los Monteros, H. V. E.; Jia, W.; Huo, D.; Hou, C.; Lei, Y.; Biosens. Bioelectron. 2012, 31, 426.

29. Ensafi, A. A.; Abarghoui, M. M.; Rezaei, B.; Sens. Actuators, B 2014, 196, 398.

30. Yang, Y. J.; Zi, J.; Li, W.; Electrochim. Acta 2014, 115, 126.

31. Bard, A. J.; Faulkner, R. W. In Electrochemical Methods, Fundamentals and Applications; Wiley: New York, 2004, p. 23.
32. Jafarian, M.; Haghighatbin, M.; Gobal, F.; Mahjani, M.; Rayati, S.; J. Electroanal. Chem. 2011, 663, 14.

33. Majidi, M. R.; Pournaghi-Azar, M. H.; Saadatirad, A.; Alipour, E.; Food Anal. Methods 2015, 8, 1067.

34. Cui, X.; Li, Z.; Yang, Y.; Zhang, W.; Wang, Q.; Electroanalysis 2008, 20, 970.

35. Ivandini, T. A.; Sato, R.; Makide, Y.; Fujishima, A.; Einaga, Y.; Diamond Relat. Mater. 2005, 14, 2133.

36. Li, Z.; Cui, X.; Zheng, J.; Wang, Q.; Lin, Y.; Anal. Chim. Acta 2007, 597, 238.

37. Valentini, F.; Amine, A.; Orlanducci, S.; Terranova, M. L.; Palleschi, G.; Anal. Chem. 2003, 75, 5413.

38. Narang, J.; Chauhan, N.; Pundir, C.; Analyst 2011, 136, 4460.

39. Luo, L.; Li, F.; Zhu, L.; Zhang, Z.; Ding, Y.; Deng, D.; Electrochim. Acta 2012, 77, 179.

40. Karuppiah, C.; Palanisamy, S.; Chen, S.-M.; Electrocatalysis 2014, 5, 177.

41. Harrison, R.; Int. Dairy J. 2006, 16, 546.

Submitted: February 23, 2016

Published online: August 12, 2016 